\title{
Characterization of Drainage Concrete in Roads Pavements Construction
}

\author{
José Ximenes ${ }^{1}$, José B. Aguiar ${ }^{1}$, Jorge C. Pais ${ }^{1}$ \\ 1. Department of Civil Engineering, School of Engineering, University of Minho, Cam- \\ pus de Azurém, 4800-058 Guimarães, Portugal. \\ Id7465@alunos.uminho.pt
}

\begin{abstract}
The application of concrete in road construction continues to be intense and, in view of the existence of a negative sustainable impact of this material, the development and knowledge of new types that minimize such actions is imperative in the face of new concerns in the context of sustainability.

The engineering works have, over time, a significant technological evolution that has provided a better serviceability to the users. As a result of this growth, the characterization and performance of these products and systems, both built and under development, are issues that have preoccupied several sectors of construction civilization, which demands more intense studies about deleterious configurations.

This work presents the study of drainage concrete for road pavements, require knowledge of physical and mechanical characteristics of materials. In order to evaluate the behavior of pavements, experimental tests were carried out with several compositions.

The rigid pavements with drainage concrete after their construction undergo under the action of traffic and atmospheric conditions. The degradation process occurs over the lifetime of the pavement and may be reduced if it is well constructed and well maintained. In this way it is fundamental to understand which are the tests that must be carried out. In the case of concrete, we have the workability, tests of resistance to compression and bending, permeability tests, compressive strength tests, wear resistance tests, and absorption by immersion tests.
\end{abstract}

Keywords: Characterization, Drainage concrete, Permeability, Compressive strength, Wear resistance, Absorption by immersion.

\section{INTRODUCTION}

Drainage concrete is a material with the same basic components as the standard concrete but designed to have high porosity. With voids content between $11 \%$ and $35 \%$ $[1,2]$ a pervious concrete mixture is composed by cement, water, and coarse aggregate with or without a small amount of fine aggregate [3]. Since pore connectivity is essential for the pervious concrete functions, its compaction is restricted [4] because it can result in a layer of cement paste at the bottom of the concrete structure that would negatively affect permeability. The installation of pervious concrete into the pavement is similar to the installation of asphalt. However, unlike the asphalt, pervious concrete 
needs to be cured until reaching the required strength. Pervious concrete as a material was used for the first time in 1852 [5].

Pervious concrete is an innovative pavement material particularly sponsored by governments because of its environmental aspects that are particularly favorable in urban areas. Pervious concrete pavement is defined as a best management practice by the US Environmental Protection Agency (EPA) for pollutions control and storm water management [6]. In the urban environment another important life-quality aspect is noise reductions; Thus a favorable aspect of pervious concrete is the capability to absorb the tire-pavement noise [7]. Regarding the quality of water and air, it is proved that the use of pervious concrete can reduce traffic pollutant. In fact, in the pervious concrete porous structure retains part of the urban solid pollutant (as zinc and copper) in its porous matrix [8].

The main function of a road pavement is to provide a free and stable surface for the use of vehicles in conditions of safety, comfort and economy. In order to fulfill this function, the surface of the pavement must have certain characteristics, known as functional characteristics, such as adhesion, geometric regularity and drainage capacity of surface water [9]. In recent decades there has been a significant increase in traffic on roads around the world. Driving now involves greater risks for the road user. To reduce some of these risks, road conditions in general and skid resistance in particular are of utmost importance. The user must respect the traffic rules while the engineers in charge of the roads have the duty to provide a safe design in particular, in the route, in the road signs and in the choice of the type of pavement.

The functional characteristics of pavements are increasingly valued, resulting from the search for better levels of safety. However, the most common methods of road pavement design only take into account the structural capacity of the same, and, therefore, it is necessary to acquire more knowledge in the area of functional properties [10]. It is important for the design / planning of the materials mixtures to meet the requirements of viability, strength and durability [11].

This article presents the results of a study developed in order to formulate a permeable concrete for road pavement. The permeability in road pavements, particularly in the drainage rigid pavement that compose them, assumes a relevant role in their performance, influencing aspects such as safety and comfort in circulation and their durability [11]. Other important properties are the mechanical ones like compressive and tensile strengths.

\section{RESULTS AND DISCUSSION}

\subsection{Materials}

\subsubsection{Cement}

Portland Cement CEM I 42.5 R A-LL was selected for this study according to EN 197-1 [12], supplied by the company SECIL. The four mixes a, b, c and d, characterized by different quantities of cement $(\mathrm{W} / \mathrm{C}=0,4)[13]$. 


\subsubsection{Water}

The classification of water types and their suitability for the manufacture of concrete is in NP EN 1008 [14]. The drinking water was used for this study.

\subsubsection{Aggregates}

The aggregates of size 4/10 and 6/12 were provided by the company Brita Minho and SECIL Portugal. The sand or fine aggregate $0 / 4$ was provided by company MIBA Portugal [15].

The control mixes had the same aggregate distribution curve composed of $80 \%$ aggregate between $4 / 10 \mathrm{~mm}$ and $20 \%$ of $6 / 12 \mathrm{~mm}$ of aggregate size. Table 1 presents the characteristics of the materials used in the permeable concrete.

Table 1. Characteristics of the materials used in permeable concrete

\begin{tabular}{llll}
\hline $\begin{array}{c}\text { Type of ma- } \\
\text { terials }\end{array}$ & Classification & D max. $(\mathrm{mm})$ & $\begin{array}{c}\text { Volumic Mass } \\
\left(\mathrm{Kg} / \mathrm{m}^{3}\right)\end{array}$ \\
\hline Cement I & 42.5 & 0.063 & $\gamma \mathrm{s}=3120$ \\
Sand & $0 / 4$ & 4 & $\gamma \mathrm{s}=2660$ \\
Aggregate & $4 / 10$ & 10 & $\gamma \mathrm{s}=2620$ \\
Aggregate & $6.3 / 12$ & 12 & $\gamma \mathrm{s}=2630$ \\
Water & Drinking & - & $\gamma \mathrm{s}=1000$ \\
\hline
\end{tabular}

\subsection{Composition of the permeable concrete}

According to the procedures referred in item 15.03.2.2-3 [10], the following shall be taken into account. Three mixtures of concrete with a percentage of fine and coarse aggregate and the quantity of the different cement percentage are applied:

The test started with $33.3 \%, 26.6 \%$ and $20 \%$ of fine aggregate $0 / 4$ and the rest were the aggregates of $4 / 10$ and $6 / 12$, the cement was $300 \mathrm{~kg} / \mathrm{m}^{3}$

The following tests were made with different quantities of cement $\mathrm{M} 1=271, \mathrm{M} 2=$ $300, \mathrm{M} 3=350$ and $\mathrm{M} 4=400 \mathrm{~kg} / \mathrm{m}^{3}$ and the quantity of the aggregates was maintained.

The last tests were made with $80 \%$ of aggregate $6 / 12$ and $10 \%$ aggregate of $4 / 10$ and the amount of cement maintains $300 \mathrm{~kg} / \mathrm{m}^{3}$.

Figure 1 presents the results of the granulometric analysis of the aggregates selected according to the fractions indicated in [10] or NP EN 933-2 [16]. 


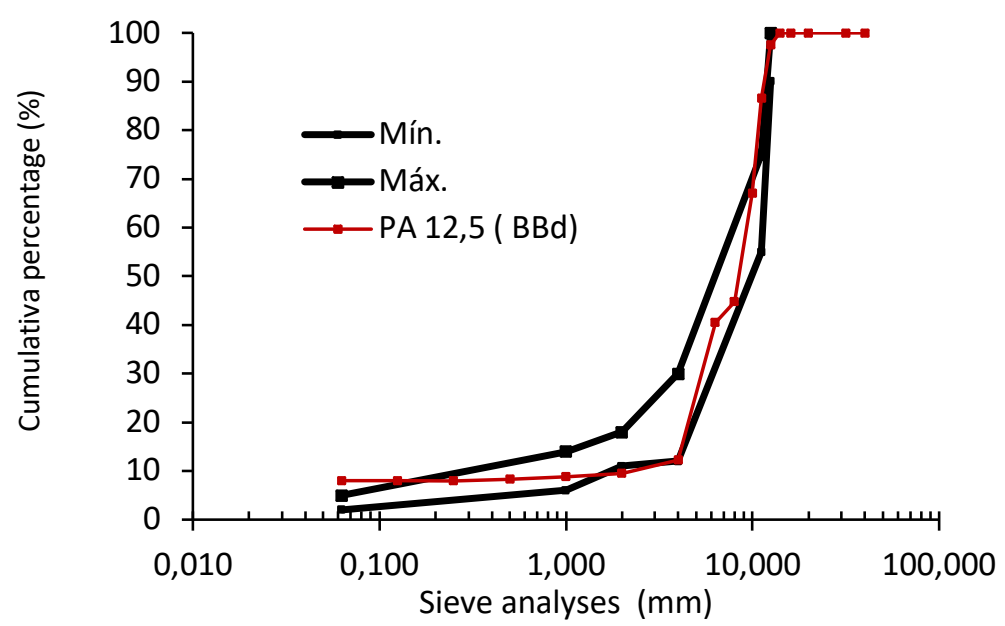

Fig. 1. Mixing of the permeable concrete inside the granulometric spindle of BBd-PA 12.5 (Drainage bituminous concrete - Asphalt porosity)

Table 2 presents the composition of the concretes comparison [17, 18, 19].

Table 2. Compositions of the concretes comparison

\begin{tabular}{ccccc}
\hline References and No. & years & $\begin{array}{c}\text { Cementitious } \\
(\mathrm{CEM} \mathrm{kg} / \mathrm{m} 3)\end{array}$ & $\begin{array}{c}\text { Aggregates } \\
(\mathrm{kg} / \mathrm{m} 3)\end{array}$ & W/C \\
\hline Tennis Paul D. (ACI) & 2004 & $270-415$ & $1190-1480$ & $0,27-0,34$ \\
Ramadhansyah et al & 2014 & $400-450$ & $1115-1430$ & $0,33-0,34$ \\
R. Mahalingam at al & 2016 & $158-330$ & $1178-1421$ & $0,43-0,7$ \\
José Ximenes & 2019 & $271-400$ & $1535-2118$ & 0,4 \\
\hline
\end{tabular}

\subsection{Air content}

The porosity of the permeable concrete represents the empty spaces existing in the continuous medium formed by the constituent minerals of the matrix. The presence of the pores and the development of these voids are closely related to the voids of the coarse aggregates. The number of voids is evaluated by the porosity (n), which is the ratio between the void volume of a sample of drainage concrete and its total volume (Equation 1).

$$
\mathrm{n}=\frac{\mathrm{np}}{\mathrm{vt}} \times 100
$$


$\mathrm{n}=$ Porosity of the specimen

$\mathrm{np}=$ Volume of the permeable concrete voids

$\mathrm{Vt}=$ Total volume

The porosity is usually expressed as a volume percentage considering $10 \%$ permeable concrete as an average value, $5 \%$ a low value and $15 \%$ a high value. The voids are constituted by the pores and cracks of the draining concrete and are necessarily all interconnected.

\subsection{Test of the fresh concrete}

In the execution of the concrete mixtures, a concrete mixer with a vertical axis was used, with a capacity of 90 liters. After the kneading and before filling the molds, the slump test according to standard NP EN 12350-2 [20] was carried out for each mixture with the Abrams cone. The values obtained for slump are $0 \mathrm{~mm}$.

The spreading test was made according [21]. This test gave the results shown, between 400 and $450 \mathrm{~mm}$ (F2 and F3).

Table 3 presents the variation of the fresh density with the amount of binder. As expected, the bulk density increased with the cement quantity. This constituent has the higher volumic mass.

Table 3. Fresh concrete test

\begin{tabular}{clccc}
\hline No. & Test of fresh & Norms & \multicolumn{2}{c}{ Results } \\
\hline 1 & $\begin{array}{l}\text { Granulometric } \\
\text { Mixing content }\end{array}$ & Granulometric spindle & Follows the norm & Ok \\
2 & the blend & Quantity Cement & $16-22 \%$ & Ok \\
3 & Lowering & Class S1 - S5 & $0 \mathrm{~mm}$ & \pm Ok \\
4 & Spreading & Table F2 e F3 $(\mathrm{mm})$ & $400-450 \mathrm{~mm}$ & Ok \\
5 & Density & $\geq 2000 \mathrm{~g} / \mathrm{cm}^{3}$ & $2000-2225 \mathrm{~g} / \mathrm{cm}^{3}$ & Ok \\
\hline
\end{tabular}

Specimens were molded for different tests (Figure 4):

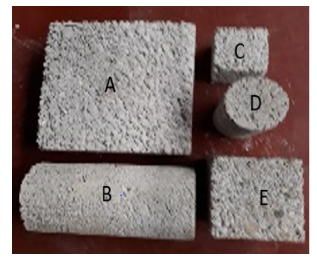

Fig. 2. Specimens for different tests
A. $30 \times 30 \times 9.5 \mathrm{~cm} 3$ specimens for the permeability test;

B. Diameter $\varnothing 15 \times 30 \mathrm{~cm}$ cylinder for the tensile strength test by compression;

C. $10 \times 10 \times 10 \mathrm{~cm} 3$ specimens for water absorption test;

D. Cylinder $\varnothing 10 \times 15 \mathrm{~cm}$ for wear resistance;

E. Specimens of $15 \times 15 \times 15 \mathrm{~cm} 3$ for compressive strength. 
The standard NP EN 12390-2 [22] suggests leaving the specimen inside the mold between 16 and 72 hours, protected against shocks, excessive vibrations and dehydration at a temperature of $20 \pm 5^{\circ} \mathrm{C}$. All specimens remained within the mold until the age of 24 hours. After the molds were removed, the specimens were placed in water at a temperature of $20 \pm 2{ }^{\circ} \mathrm{C}$ till the tests dates.

\subsection{Permeability tests}

According to the results obtained for each of the mixtures tested, the percentage of aggregates and compaction energy will be selected in order to obtain a value of the porosity and the preserved strength defined in item 14.03. 2.4 [10] for the mixture concerned. The water permeability values measured with the LCS permeation test should be between 10 and 30 seconds [23]. If it is found that both percentages of aggregate used meet the specifications defined in 14.03.2.4 [10] for the mixture in question, the lowest shall be adopted.

The Figure 3 represents one permeability test. The results are presented in Table 4 and Figure 4. The values are between 10 and 30 seconds according to the standard except the value for the composition with CEM $400 \mathrm{~kg} / \mathrm{m}^{3}$ (Table 4). This means that the permeability decreases with the increase of the cement content. It is not appropriate to use more than $350 \mathrm{~kg} / \mathrm{m}^{3}$ of cement content.

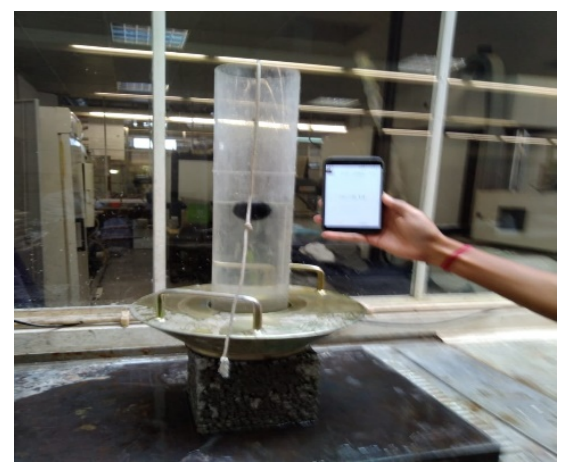

Fig. 3. Permeability tests

Table 4. Permeability Tests

\begin{tabular}{ccc}
\hline \multicolumn{3}{c}{ Permeability (s) } \\
Mixtures & $\begin{array}{c}\text { CEM } \\
\left(\mathrm{kg} / \mathrm{m}^{3}\right)\end{array}$ & Flow Time (s) \\
\hline M1 & 271 & 16.73 \\
M2 & 300 & 18.15 \\
M3 & 350 & 22.66 \\
M4 & 400 & 33.49 \\
\hline
\end{tabular}




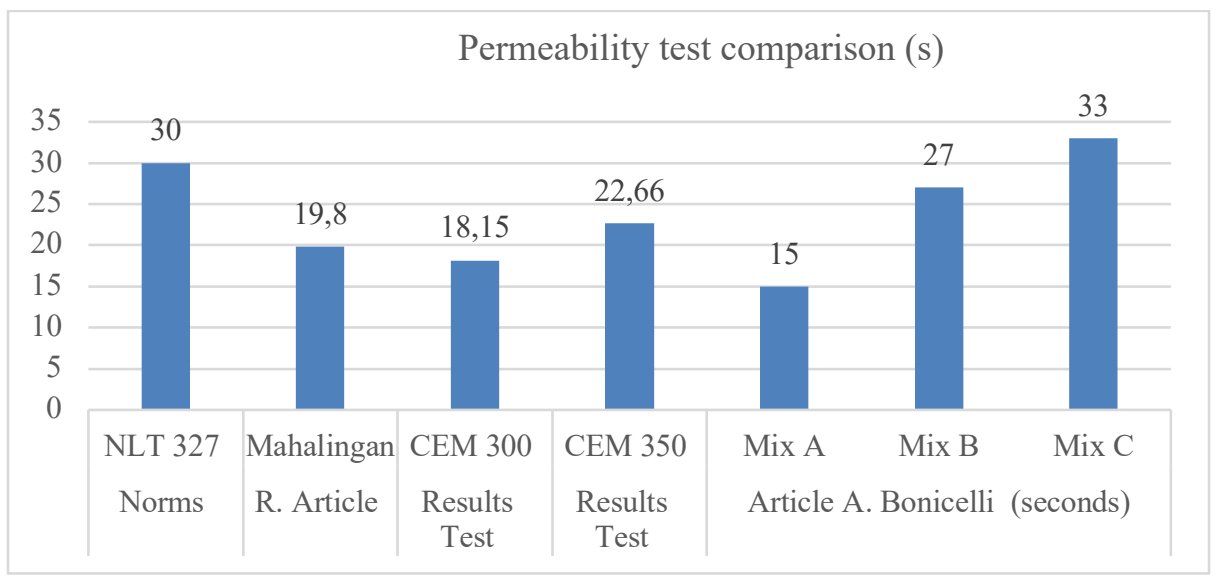

Fig. 4. Permeability test results comparison

\subsection{Compressive strength tests}

Compressive strength is a very important parameter for deciding on the concrete quality and performance. The compressive strength test was conducted according to NP EN 206:2013 +A1 [21]. Cube specimens measuring $150 \mathrm{~mm}$ x $150 \mathrm{~mm}$ x $150 \mathrm{~mm}$ were prepared for each mix and tested.

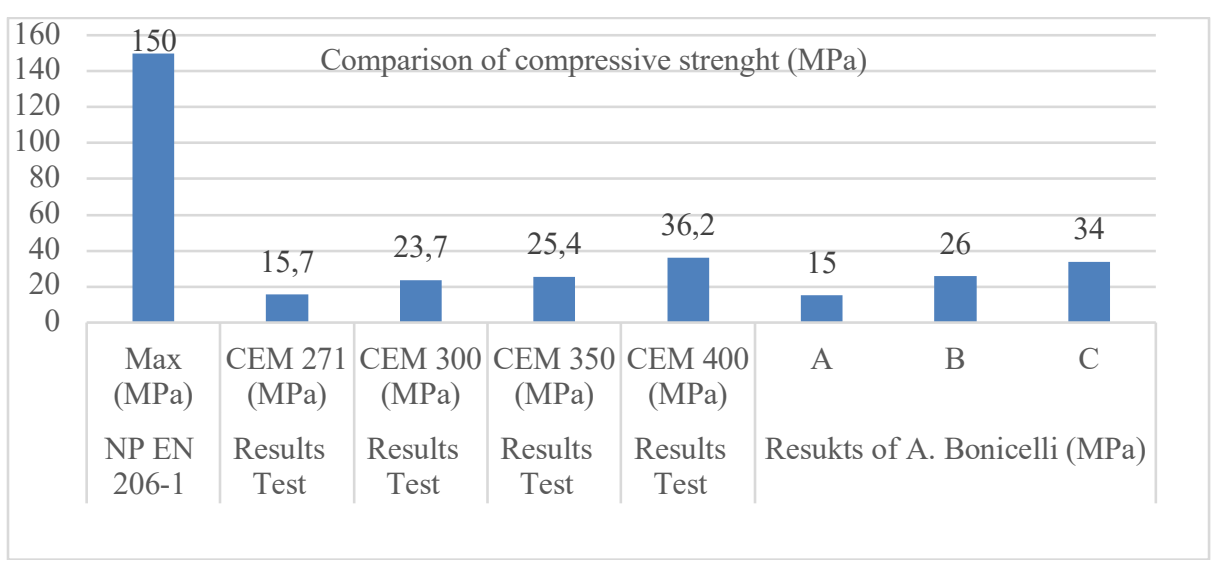

Fig. 5. Results of compressive strength of concrete comparison

The results of compressive strength are in Fig. 5. It was possible to achieve a compressive strength between 15,7 and $36.2 \mathrm{MPa}$. The satisfactory values for road pavement is from 23 to $36 \mathrm{MPa}$. 


\subsection{Tensile strength tests}

In order to determine the tensile strength of the drainage concrete, hydraulic compression equipment was used (Figure 6). The test was developed at a speed of $1.5 \mathrm{kN} / \mathrm{s}$ according to the size of the cylinder with diameter $\varnothing 150 \mathrm{~mm}$ and height of $300 \mathrm{~mm}$.

The tensile strength by compression reaches values between 8 to $9.3 \mathrm{MPa}$. This is an adequate result for the application on road pavements. The tensile strength was only determined for the mixes with higher compressive strength and that respect also the requirement for the permeability test.

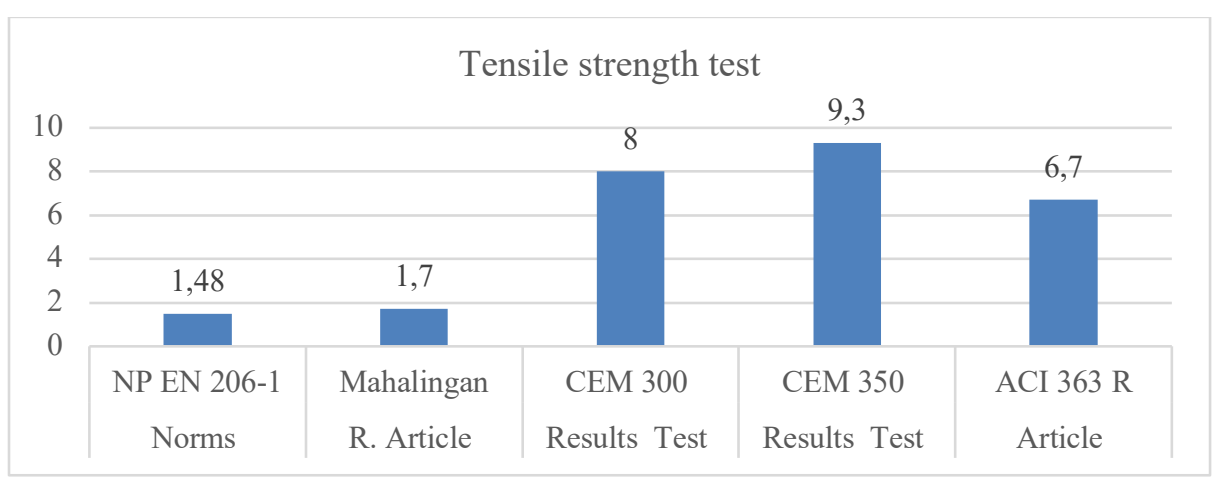

Fig. 6. - Comparison Testing of tensile strength tests by compression

\subsection{Immersion test}

Another form of water absorption in the concrete derives from its immersion, which directly influences its durability. The test in question permits the quantification of the volume of accessible voids in the concrete mass.

The methodology of this laboratory test followed the specification LNEC E-394 [25]. In performing the test, it was necessary to resort to the equipment described later.

Precision balance of $\pm 0,05 \%$ of the mass to be used; - Hydrostatic balance; Ventilated oven at $110 \pm 5^{\circ} \mathrm{C}$; - Container with water. The geometry of the specimens chosen to analyze the water absorption by immersion in the concrete produced was the cube with the dimension of $100 \times 100 \times 100 \mathrm{~mm}^{3}$ with 28 days of cure [26]. The specimens were placed in the vessel with water such that they were immersed in $1 / 3$ of their height during the period of one hour; The process was repeated by adding water to the vessel to make up $2 / 3$ and the entire height of the specimens, both in onehour periods. The samples were then allowed to reach constant mass, and their masses were then recorded with dry surface - M1 - and hydrostatic mass after saturation $\mathrm{M} 2$; The specimens were dried in the oven at $110 \pm 5^{\circ} \mathrm{C}$ until constant mass and the masses -M3 were recorded. 
After all the tasks performed, the values were treated as indicated in Fig 7. It was possible to analyze the results obtained for the water absorption by immersion of the concrete specimens determined from the following equation:

$$
\text { Ai }(\%)=\frac{M 1-M 3}{M 1-M 2} \times 100
$$

$\mathrm{Ai}=$ absorption of water by immersion (\%);

$\mathrm{M} 1=$ mass of the test specimen saturated with dry surface $(\mathrm{g})$;

M2 = hydrostatic mass of the saturated sample $(\mathrm{g})$;

M3 = mass of the oven dried specimen $(\mathrm{g})$.

Finally, the absorption of water by immersion was obtained by percentage of mass, as indicated. It is possible to analyze in a comprehensible way the water absorption by immersion in Fig 7 for different test specimens of the traces of draining concrete.

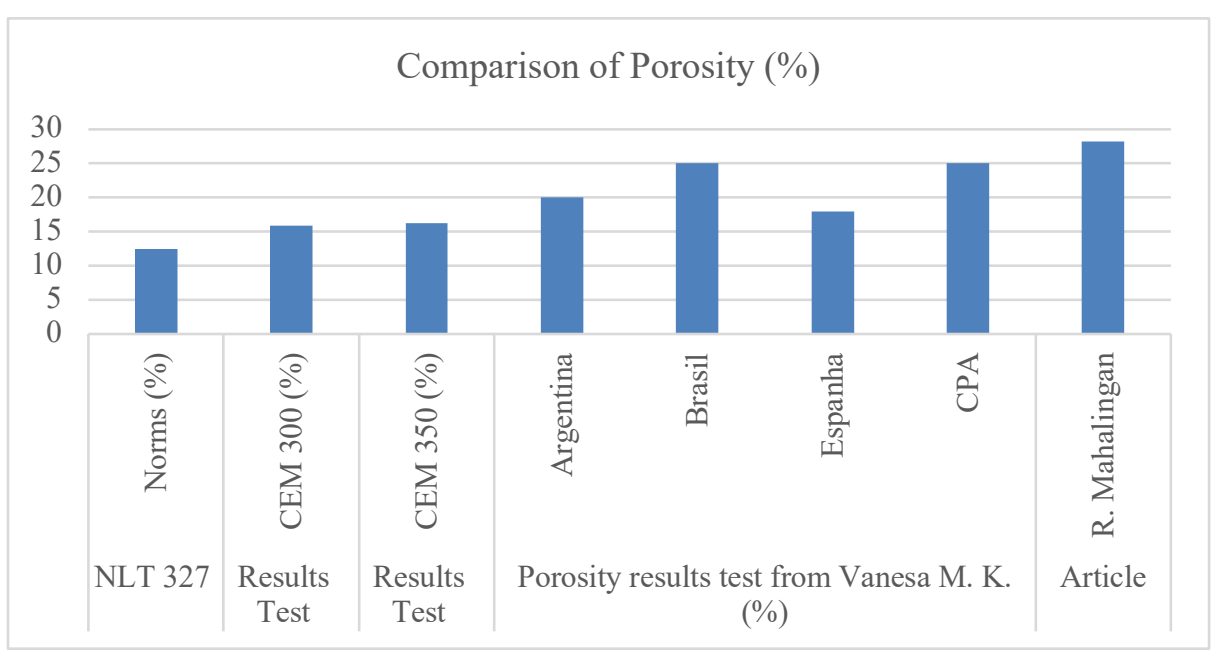

Fig. 7. Immersion absorption values for the compositions studied

\subsection{Wear resistance test}

At the beginning of the test the specimens are inserted into the drum. The time the drum should rotate is normalized. The machine rotates 300 revolutions, at a constant speed of 30 to $33 \mathrm{r} / \mathrm{min}$ according to standard NP EN 1097-2 [27].

In Spain the bituminous mixtures formulation method uses the Cantabrian test developed with the purpose of evaluating the wear loss of the bearing layer. This test consists in the determination of the mass loss of cylindrical drain concrete specimens (Ø100 mm and height of $150 \mathrm{~mm}$ ) submitted to 300 cycles in the Los Angeles wear machine without steel balls (Figure 8).

After the 300 rotations the test pieces were weighted, being possible to calculate the weight loss of the same ones. This test also allows indirect evaluation of cohesion, 
as well as the resistance to disintegration of the mixture before suction and the abrasive effects caused by the traffic.

The test consists of molding 6 specimens, 3 of which are placed in a humid chamber at $25^{\circ} \mathrm{C}$ for 672 hours and the remainder initially immersed in water at $25^{\circ} \mathrm{C}$ where they remain for 28 days and then are withdrawn from the water and kept in a free environment at $25^{\circ} \mathrm{C}$ for 24 hours. After this time the specimens are premeasured and weighted [27].

At the end of the test, the specimen is cleaned with a compressor (Figure 8). The sample is then weighted and the Los Angeles coefficient (LA) calculated from the following equation:

$$
P(\%)=\frac{P 1-P 2}{P 1} \times 100
$$
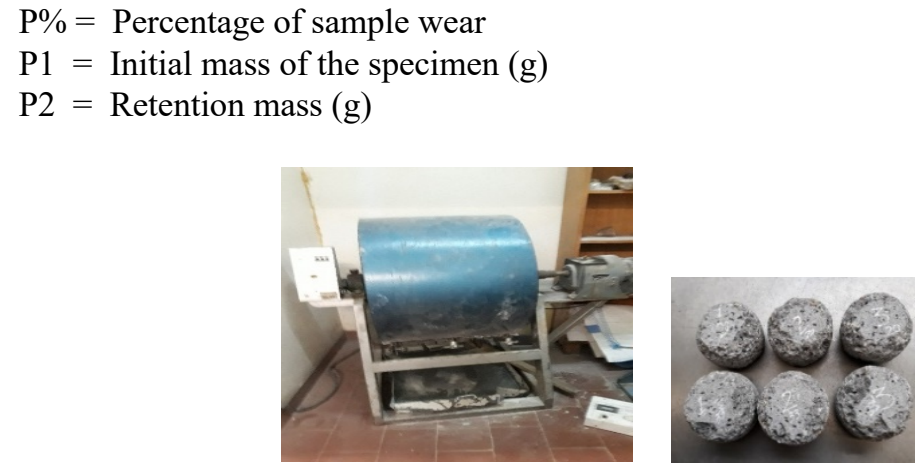

Fig. 8. Los Angeles machine and result of the test of Cantabrian

After all the tasks performed the values were treated as indicated in Fig 9. The average wear mass is between 15 and $15.8 \%$. The results show that there is no influence of the cement amount.

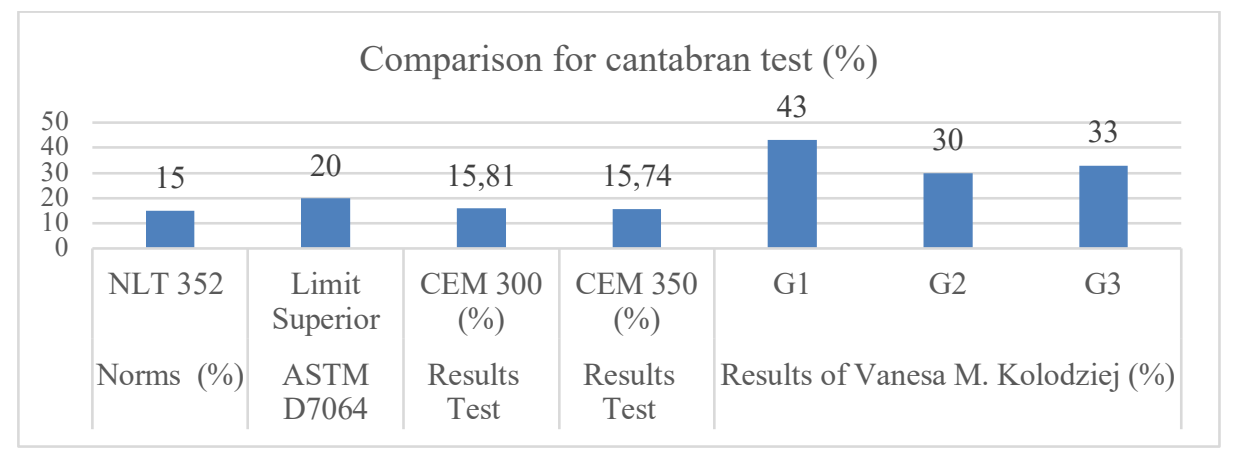

Fig. 9. Cantabrian test comparison 


\section{CONCLUSION}

The main function of the permeable concrete in road pavements is to provide a free on built surface, intended for the circulation of vehicles under adequate conditions of safety, comfort and economy.

One of the main objectives was to determine the proper balance strength and permeability in order to assure the proper resistance to high traffic loads without losing the draining capacity. Specific requirements should be defined during the phase depending on estimated traffic levels and climate conditions of the construction site.

An experimental program was defined by granulometric analysis and comprising the formulation of different compositions and the respective characterization of the concrete produced by evaluating its average permeability of 16-23 seconds and compressive strength of $20-36 \mathrm{MPa}$. Two mixtures were related because the properties are adequate for the production of drainage concrete. These mixtures have 300 and $350 \mathrm{~kg} / \mathrm{m} 3$ of cement content.

\section{REFERENCES}

1. I. N. Grubeša, I. Barišić, V. Ducman, and L. Korat,: "Draining capability of single-sized pervious concrete". Constr. Build. Mater., vol. 169, pp. 252-260, 2018.

2. L. Haselbach, M. Boyer, J. Kevern, and V. Schaefer,: "Cyclic Heat Island Impacts on Traditional Versus Pervious Concrete Pavement Systems". Transp. Res. Rec. J. Transp. Res. Board, vol. 2240, pp. 107-115, 2011.

3. B. Huang, H. Wu, X. Shu, and E. G. Burdette,: "Laboratory evaluation of permeability and strength of polymer-modified pervious concrete". Constr. Build. Mater., vol. 24, no. 5, pp. $818-823,2010$

4. A. M. Amde et al.,: "State Highway Administration Research Report Development of High Quality Pervious Concrete Specifications for Maryland Conditions. Md-13Sp009B4F," p. February, 2013.

5. G. H. Qoja,: "STUDY OF SOME PROPERTIES OF NO - FINES". vol. 7, no. 1, pp. 4753, 2016.

6. A. J. N. B. J. Putman,: "Comparison of test specimen preparation techniques for pervious concrete pavements". p. build, mat, 2011

7. A. Bonicelli, M. Crispino, F. Giustozzi, and M. Shink,: "Laboratory Analysis for Investigating the Impact of Compaction on the Properties of Pervious Concrete Mixtures for Road Pavements”. Adv. Mater. Res., vol. 723, pp. 409-419, 2013.

8. A. Bonicelli, F. Giustozzi, M. Crispino, and M. Borsa,: "Investigation on the functional and mechanical performance of differentially compacted pervious concrete for road pavements". pp. 265-272, 2014.

9. M. Menezes,: "Study of surface characteristics of road pavements for traffic safety analysis". University Lisbon," p. Dissertati, 2008.

10. E.P. - Estradas de Portugal,: "Pavientação, Características dos materiais," no. Caderno de Encargos Tipo Obras. 14.03-, p. 125, Lisboa.Portugal, 2014.

11. J. L. B. de Aguiar,: "Building materials; stones - binders - mortars - woods - metals ". p. University of Minho, Guimarães Portugal, 2007. 
12. IPQ - NP EN 197-1, : "Cement Part 1: Composition Specifications and Conformity Criteria for Standard Cements". p. Portuguese, 2012.

13. APEB - NP EN 206-1,: "A Especificação do Betão. Guia para a utilização da norma," no. Instituto Português da Qualidade. p. 19, Lisboa, Portugal., 2008.

14. IPQ - NP EN 1008,: "Water for use in construction,”. p. Portuguese Quality Institute, Caparica, Lisbo, 2003.

15. Mibal, "Declaration of Performance No 03 - rev.01 - White Sand Mibal .... pdf. "," p. Braga Portugal, 2004., 2004.

16. IPQ - NP EN 933-2,: "Tests to determine the geometric characteristics of the aggregates. Part 2: Determination of the granulometric distribution. Test sieves, nominal size of the apertures". p. Portuguese Quality Institute, Caparica, Lisbon, 1999.

17. Tennis, Paul, D.; Leming, Michael, L.; and Akers, David, J., Pervious Concrete Pavements, EB302.02, Portland Cement Association, Skokie, Illinois, and National Ready Mixed Concrete Association,Silver Spring, Maryland, USA, 2004, 36 pages.

18. Ramadhansyah putra jaya, et al: A Review of Porous Concrete Pavement: Applications and Engineering Properties 2014

19. Rama Mahalingam at al: Analysis of pervious concrete properties 2016

20. IPQ - NP EN 12350-2,: "Tests of fresh concrete. Part 2: Lowering test". Instituto Português da Qualidade, p. Caparica, Lisboa, 2009.

21. IPQ - NP EN 206:2013 +A1,: "Concrete Specification, Performance, Production and Compliance Concrete”. Instituto Portuguesa da qualidade, p. 1-29, Caparica, Lisboa, 2005.

22. IPQ - NP EN 12390-2,: "Testing hardened concrete- Part 2: Making and curing specimens for strength tests". p. Instituto Português da Qualidade, Caparica, Lisboa, 2009.

23. ASTM/C1754M,: "Standard test Method for density and void content of hardened pervious concrete". p. ASTM/C1754M-12: United States, 2012.

24. NLT - 362/92,: "Efecto Del agua sobre la cohesión de mezclas betuminosas de granulametriia abierta, mediante el ensayo cántabro de perdida por desgaste”. p. NLT362/92, 1992

25. LNEC - E 394, : "Concretes. Determination of water absorption by immersion. Test at atmospheric pressure". p. National Civil Engineering Laboratory, Lisbon, 1993.

26. IPQ - NP EN 12390-2,: "Hardened concrete tests. Part 2: Execution and curing of test pieces for mechanical strength tests". p. Portuguese Quality Institute, Caparica, Lisbon, 2009.

27. NP EN 1097-2,: "Los Angeles Machine Wear Resistance Test". p. Instituto Português da Qualidade, Caparica, Lisboa, 2002. 